\title{
Physical Education in Kindergarten Promotes Fundamental Motor Skill Development
}

\author{
Anderson G. Lemos ${ }^{1}$, Eric L. Avigo ${ }^{2}$, José A. Barela ${ }^{1,2,3}$ \\ ${ }^{1}$ Graduate Program, Human Movement Science, Institute of Physical Activity and Sport Sciences, \\ Cruzeiro do Sul University, São Paulo, Brazil \\ ${ }^{2}$ Institute of Physical Activity and Sport Sciences, Cruzeiro do Sul University, São Paulo, Brazil \\ ${ }^{3}$ Department of Physical Education, Institute of Biosciences, São Paulo State University, Rio Claro, Brazil \\ Email: jose.barela@cruzeirodosul.edu.br
}

Received October $8^{\text {th }}$, 2011; revised November $10^{\text {th }}$, 2011; accepted November $21^{\text {st }}, 2011$

\begin{abstract}
Skill development is influenced by many factors and, among many, opportunity of practice and appropriate instruction provided by teacher might be considered as key elements but still need to be empirically investigated. Therefore, the purpose of this study was to compare gross motor development of young children enrolled in physical education, provided by a specialist teacher, and children enrolled in recreational activities, provided by a regular teacher, in kindergarten. Fifty children were divided into two groups: 25 children (age of $5.3 \pm 0.3$ years) constituted the physical education (PE) group and received activities, once a week, ministered by a physical education teacher; 25 children (age of $5.2 \pm 0.4$ years) constituted the recreational (RE) group and received activities, also once a week, supervised by a classroom teacher. All these children were evaluated performing the locomotor and object control subtests of Test of Gross Motor Development (TGMD-2) at the beginning and at the end of the school year. Performance of both subtests were scored, according to the performance criteria of TGMD-2, by three experimenters, obtaining the raw skill score and the equivalent motor age for each subtest. Results revealed that both children's groups showed similar raw skill score and equivalent motor age before enrollment in any activities, at the beginning of the year. Differently, after enrolment in the respective activities, PE children showed higher raw skill score and equivalent motor age than RE children. These results demonstrated that regular physical education, composed by structured practice, ministered by a specialist promote gross motor development of children even at young age such as in kindergarten.
\end{abstract}

Keywords: Physical Education; Children; School; Gross Motor Development

\section{Introduction}

Although debatable, fundamental motor skills are considered as building blocks of latter motor skill acquisition related to sport-specific movements (Clark, 1994; Gallahue, 1982) and skillfulness (Clark, 1994). Moreover, if gross motor development is not mastered, children may experience lifelong difficulties with later motor skill acquisition. Therefore, the acquisition of gross motor skill is critical, but despite its importance, unfortunately, gross motor development has been overlooked by many who work with early education (Clark, 2007).

Many might be the reasons for little attention to gross motor skill acquisition, but the main reason comes from the assumption that maturation would underlie gross motor or fundamental motor skill development. Undoubtedly maturation plays an important role in motor development course and acquisition rate, but it might not be considered the sole factor contributing to motor skill development (Thelen, 1986; Ulrich, 1989). Actually, the idea that maturation is the driving force responsible to early motor skill acquisition is a misconception that limited our understanding of the early underlying motor development processes. Moreover, since maturation was though to be the driven force for early motor skill acquisition, these skills were not required to be taught in daily physical education in kindergarten and even in early elementary school years.

The misconception describe above, according to Clark (2007), is due to the fact that early infants' motor acquisition does not have to be taught: infants learn how to sit, stand, and walk, for instance, by themselves and latter the same happens with toddlers running, jumping, and throwing. Since these early skill acquisitions seem not require instruction or structured practice, the misconception that maturation as the sole driving force pervaded early motor development understanding.

Despite happening without specific instruction and practice, several researchers have question factors other than maturation affecting even the so called fundamental motor pattern (Gallahue, 1982) and even suggested, based on unpublished data, that “... the results of these and other investigations indicate that the fundamental movement phase of development is greatly influenced by environmental factors” (Gallahue, 1982: p. 248), which we may add such as structured practice and instructions provided by a teacher. Recently, Gallahue and Donnelly (2007) have suggested that physical education in early school intervention is the only place where children would be instructed and intervened in order to achieve proficiency in fundamental motor patterns.

Recent explanations about motor development have emphasized that motor skills change through interactive processes between the individual and the environment (Clark, 1994; Thelen, 1995, 2000). In such a view, despite changes occurring in many of the biological systems, which drive some of the developmental changes, our biological heritage is modulated continuously by 
our interaction with the environment (Clark, 2007), which provides us with adaptation and learning. Many are the environmental factors that might affect early motor skill acquisition, but structured practice and instructions should be provided to all children from kindergarten to high school. Moreover, these conditions should be designed in order to help children to acquire and, more importantly, refine motor skills in order to become proficient (Clark, 2007). Therefore, the role of physical activity in early school is critical and crucial for children's motor development proficiency.

Despite all its importance, the effects of early physical education intervention, as part of school program, still need to be showed. One difficulty in doing so is that motor development throughout the first school years undergoes dramatic changes that make the evaluation progress much complicated. Moreover, motor development in these early years should be assessed primarily in the gross motor skill pattern instead of quantitative motor performance. A test that might be used to early motor development assessment, among many (Cools, Martelaer, Samaey, \& Andrias, 2008), is the Test of Gross Motor Development, second edition (TGMD-2) (Ulrich, 2000). Several studies have used the TGMD-2 to assess fundamental motor skill proficiency in typical (Bonifacci, 2004; Pang \& Fong, 2009) and delayed developmental children (Bonifacci, 2004; Valentini \& Rudisill, 2004) as well in children with special needs (Houwen, Hartman, Jonker, \& Visscher, 2010; Niemeijer, Smits-Engelsman, \& Schoemaker, 2007; Staples \& Reid, 2010).

Considering that the TGMD-2 might provide useful information regarding children's gross motor development and its progress throughout the school age (Ulrich, 2000) and that the effects of physical education activities in children's motor development still need to be examined, the purpose of this study was to examine the gross motor development of children enrolled in regular physical education activities, provided by a specialist, and children enrolled in recreational activities provided by a regular teacher, in kindergarten. Our main hypothesis was that gross motor development of children enrolled in regular physical education, provided by a specialist, would be superior of that observed of children enrolled in recreational activities.

\section{Methods}

\section{Participants}

Fifty healthy children, aging from 5- to 6-year-old, from a public school of Guarulhos city, São Paulo metropolitan area, were selected to participate in this study. Children constituted two groups that were randomly assigned to be exposed to different physical activities throughout the last kindergarten year. Twenty-five children (15 boys and 10 girls) were enrolled in physical education activities, 50-minute session ministered once a week by a physical education specialist, and 25 children (14 boys and 11 girls) were enrolled in recreational activities, 50-minute session provided also once a week by the classroom teacher. Prior to enrollment in the study, children's parents were informed about the experimental procedures and provided a written informed consent form approved by the Institutional Review Board.

Children assigned to the physical education activity group (PE) experienced, throughout the school year, activities ministered by a physical education teacher. These physical education activities followed the educational kindergarten guidelines, which was composed by cooperative games and activities involving fundamental motor skills in an enjoyable and playful environment. Children assigned to the recreational activity group (RE) experienced, throughout the school year, activities mostly developed in the school playground, with children playing by themselves under the supervision of the classroom teacher.

\section{Procedures}

The TGMD-2 (Ulrich, 2000) was employed in this study in order to assess fundamental motor abilities. All data collection was conducted in the school facility. Prior to testing, children's anthropometric information, height and body mass, was obtained. Following, children were videotaped performing both locomotor and object control subtest abilities, using two cameras (Sony-Model DCR-HC96). One camera was placed in one area of the school in such way that all the locomotor abilities could be videotaped. Similarly, the second camera was placed nearby and used to videotape all the object control abilities. A number was assigned to each child and used for all further identification during analysis.

Preceding assessment, an accurate demonstration and verbal description of the skill, following TGMD-2 instructions (Ulrich, 2000), were provided to the child by an experienced physical education instructor. After, the child was given one practice trial to assure that the child understood what to do. If the child did not appear to understand the task or had not performed correctly the practice trial, additional demonstration and instructions were provided by the same physical educator. In this case, one physical education instructor was responsible by the locomotor subtest abilities and another physical education instructor was responsible by the object control subtest abilities. Each child then performed two trials for each gross motor skill, first all the locomotor subtest abilities and then all the object control abilities. All the procedures for each child took from 15 to 20 minutes.

Children from both groups were videotaped at the beginning of school year (March-second month of the Brazilian school year) and at the end of the school year (November-last month of the Brazilian school year), therefore, children were assessed eight months apart during the last year of the kindergarten Brazilian School System. All the procedures, including the physical education instructors, who provided instructions and demonstrations, were the same in both assessments.

\section{Data Analysis}

Each child performance was rated by three physical education instructors, using the videotaped performance of each gross motor skill, both trials, reviewing the images as many time as necessary. Prior to the assessment, the raters were trained to gain competence to rate the gross motor skill following the TGMD-2 performance criteria (Ulrich, 2000). The rate training required mastering the performance criteria described in the TGMD-2 test, rating the children, and finally discussion of the reasons of any discordance. Assessment was only initiated after all raters had showed concordance above $85 \%$ of the trials, using a subgroup of children.

Following the TMGD-2 instructions (Ulrich, 2000), each gross motor skill was assessed using the performance criteria. A value of 1 or 0 was assigned to the specific performance criteria if the behavioral component was observed or absent, respectively. Summing up all the values assigned to the performance criteria 
for both trials performed by the child a total of 48 points, for each subtest, locomotor and object control, was possible. This total for each subtest abilities, following the TGMD-2 instructions (Ulrich, 2000), was considered the raw score for the locomotor and object control subtest separately, and as close to the total possible score would indicate better performance, according to the performance criteria, pooling all the gross motor skills of each test.

Based on the raw score, motor age-equivalent was obtained which indicates the developmental level or age that corresponds to the raw score obtained by the children. Motor age-equivalent was obtained for each child in both locomotor and object control subtest, following normative data (Ulrich, 2000).

\section{Statistical Analysis}

After testing the assumptions for normality and homogeneity of variance, four analyses of variance (ANOVAs) were used to test possible anthropometric differences between groups at the moment of the second assessment. The dependent variables, for each ANOVA, were chronological age, weight, height, and body mass index. Two MANOVAs were also used to test gross motor skill performance between groups and tests, with test factor treated as repeated measures. The first MANOVA had as dependent variables the raw score and motor age-equivalent for the locomotor subtest and the second MANOVA the same variables for the object control subtest. Finally, paired "t" tests were used to compare chronological age and motor age-equivalent among the respective group, test, and gross motor skill subtest.

When necessary univariate analyses were employed and $\alpha$ level for all analyses was 0.05 . All analyses were performed using the SPSS package (SPSS version 10.0).

\section{Results}

\section{Anthropometric Data}

Table 1 reveals anthropometric information of all children in each group at the moment that the second assessment occurred. ANOVAs showed no group effect for age, $F(1,48)=0.72$, $\mathrm{p}>$ 0.05 , weight, $F(1,48)=0.11, \mathrm{p}>0.05$, height, $\mathrm{F}(1,48)=0.02, \mathrm{p}$ $>0.05$, and BMI, $\mathrm{F}(1,48)=0.23$, $\mathrm{p}>0.05$.

\section{Motor Skill Performance}

Figure 1 depicts locomotor subtest raw score and equivalent motor age for children from both groups and assessments. MANOVA revealed marginal group effect, Wilks' Lambda $=0.884$, $\mathrm{F}(2,47)=3.08, \mathrm{p}=0.055$, but test effect, Wilks' Lambda $=0.749$, $\mathrm{F}(2,47)=7.85, \mathrm{p}<0.005$, and group and test interaction, Wilks' Lambda $=0.861, \mathrm{~F}(2,47)=3.79, \mathrm{p}<0.05$. Univariate analyses showed difference between groups for raw score, $\mathrm{F}(1,48)=6.26$, $\mathrm{p}$ $<0.05$, and for the equivalent motor age, $\mathrm{F}(1,48)=5.77, \mathrm{p}<0.05$. Similarly, univariate analyses revealed difference between tests for raw score, $F(1,48)=10.07, p<0.005$, and for

Table 1.

Mean and stardard deviation of chronological age, weight, height, and body mass index (BMI) of children with physical education (PE) and with recreation (RE) activities at the moment of second assessment.

\begin{tabular}{ccccc}
\hline Groups & $\begin{array}{c}\text { Age } \\
(\text { years })\end{array}$ & $\begin{array}{c}\text { Weight } \\
(\mathrm{Kg})\end{array}$ & $\begin{array}{c}\text { Height } \\
(\mathrm{m})\end{array}$ & $\begin{array}{c}\mathrm{BMI} \\
\left(\mathrm{Kg} / \mathrm{m}^{2}\right)\end{array}$ \\
\hline $\mathrm{PE}$ & $6.1(0.4)$ & $21.5(4.5)$ & $1.16(0.05)$ & $15.8(2.1)$ \\
$\mathrm{RE}$ & $6.2(0.3)$ & $21.9(3.7)$ & $1.16(0.04)$ & $16.0(2.1)$ \\
\hline
\end{tabular}

equivalent motor age, $\mathrm{F}(1,48)=14.43, \mathrm{p}<0.001$. Finally, univariate analyses also revealed group and test interaction for raw score, $\mathrm{F}(1,48)=7.73, \mathrm{p}<0.01$, and for the equivalent motor age, $F(1,48)=7.01, p<0.05$. For both variables, while in the pre-test no difference was observed between groups, in the post-test, children who were enrolled in PE activities showed raw score and equivalent motor age higher than those observed for children enrolled in RE activities.

Figure 2 depicts the object control subtest raw score and equivalent motor age for children from both groups and assessments. MANOVA revealed no group effect, Wilks' Lambda = $0.912, \mathrm{~F}(2,47)=2.26, \mathrm{p}>0.05$, but revealed test effect, Wilks' Lambda $=0.333, \mathrm{~F}(2,47)=47.11, \mathrm{p}<0.001$, and group and test interaction, Wilks’ Lambda $=0.596, \mathrm{~F}(2,47)=15.92, \mathrm{p}<0.001$. Univariate analyses revealed difference between tests for raw score, $\mathrm{F}(1,48)=89.80, \mathrm{p}<0.001$, and for the equivalent motor age, $\mathrm{F}(1,48)=69.36, \mathrm{p}<0.001$. Similarly, univariate analyses revealed group and test interaction for raw score, $F(1,48)=$ 32.48, $\mathrm{p}<0.001$, and equivalent motor age, $\mathrm{F}(1,48)=29.00, \mathrm{p}<$ 0.001 . In general, raw score and equivalent motor age were higher in the post- than in the pre-test, but the improvement in both variables was higher for the children enrolled in PE than in RE activities.

\section{Chronological and Motor Age Comparison}

Table 2 depicts chronological age and equivalent motor age for locomotor and object control subtest of PE and RE children in the first and second assessments. Paired "t" tests revealed that in the locomotor subtest, for both pre- and post-test, motor age equivalent was below the respective chronological age. Differently, paired " $\mathrm{t}$ " tests revealed that in the pre-test object control age motor equivalent did not differ from the respective chronological age, for PE and RE children. Finally, in the post-test, paired "t" did not reveal any difference for RE children, but revealed that motor age equivalent was ahead of the respective chronological age for those children enrolled in PE activities.

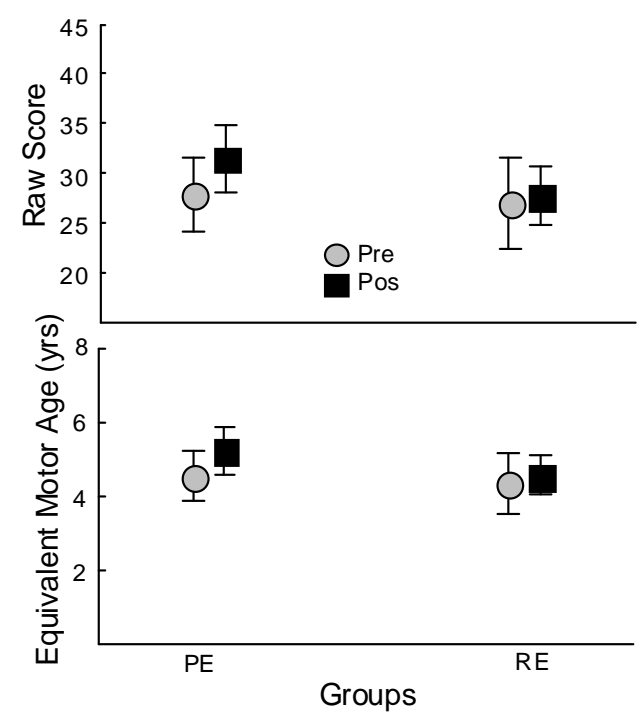

Figure 1.

Mean and standard deviation locomotor subtest raw score and equivalent motor age for children with physical education (PE) and with recreation (RE) at the first (pre) and second (post) assessment. 


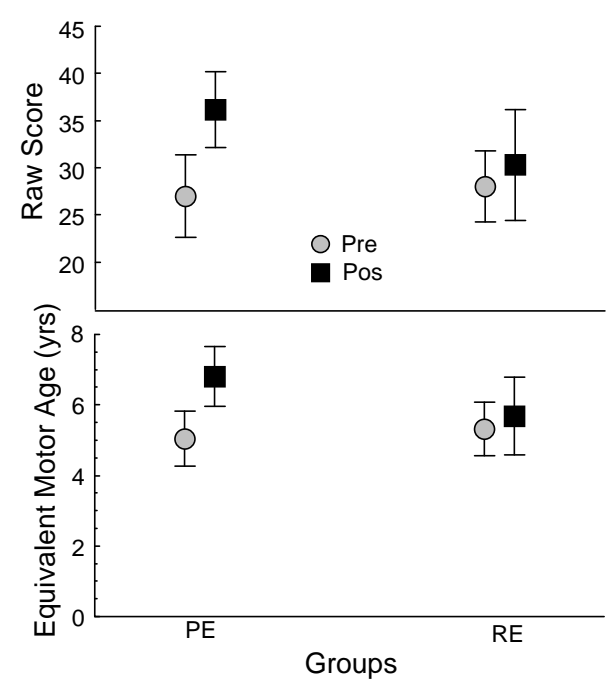

Figure 2.

Mean and standard deviation values for the object control subtest raw score and equivalent motor age for children with physical education (PE) and with recreation (RE) at the first (pre) and second (post) assessment.

Table 2.

Mean and stardard deviation of chronological age and locomotor and object control age equivalent of children with physical education (PE) and recreation (RE) at the moment of the first and second assessments.

\begin{tabular}{cccc}
\hline & $\begin{array}{c}\text { Chronological Age } \\
\text { (years) }\end{array}$ & $\begin{array}{c}\text { Locomotor Age } \\
\text { Equivalent } \\
\text { (years) }\end{array}$ & $\begin{array}{c}\text { Object Control Age } \\
\text { Equivalent } \\
\text { (years) }\end{array}$ \\
\hline PE pre & $5.3(0.3)$ & $4.5(0.6)^{*}$ & $5.0(0.7)$ \\
RE pre & $5.2(0.4)$ & $4.4(0.7)^{*}$ & $5.3(0.7)$ \\
PE pos & $6.0(0.3)$ & $5.2(0.6)^{*}$ & $6.8(0.8)^{*}$ \\
RE pos & $5.9(0.4)$ & $4.5(0.5)^{*}$ & $5.6(1.0)$ \\
\hline
\end{tabular}

Note: "indicates difference from the respective chronological age.

\section{Discussion}

The present study examined the gross motor development of children enrolled in regular physical education, provided by a specialist teacher, and children enrolled in recreational activities, provided by a regular teacher, in kindergarten. Our results showed that children from both groups prior to enrollment in the respective activities were delayed comparing the equivalent motor age to the respective chronological age in the locomotor motor skills. While at the beginning of the year no difference was observed in gross motor development, at the end of the school year, children enrolled in physical education activities, provided by a specialist, showed better performance than children enrolled in recreational activities. Physical education influence was such that, at the end of the kindergarten year, children displayed advanced object control skill development expected to their age. These results indicated that regular physical activity, provided by a specialist teacher, influences and promotes better development of gross motor development of children even in kindergarten.

Results from this study corroborate previous observations that Brazilian children are delayed in gross motor development (Braga, Krebs, Valentini, \& Tkac, 2009; Brauner \& Valentini, 2009). In this study, children were behind to the expected motor development in the locomotor skills at both moments that their skills were tested. Differently than previously observed (Brauner \& Valentini, 2009), in the present study no delay was observed in the object control skill. A possible explanation for this lack of delay in object control skills is that by this age, 5- and 6-year-old, children might not have suffer a notable lack of experience in performing manipulative tasks. Such a suggestion might be corroborated by observing that children enrolled in recreational activities, although not statistically significant, already show a tendency to fall behind in equivalent motor age comparing to the respective age, at the end of kindergarten.

Delayed performance in gross motor development observed in this study as well in previous studies (Braga, Krebs, Valentini, \& Tkac, 2009; Brauner \& Valentini, 2009) is quite preoccupant because it might lead to drastic consequences in skill acquisition in subsequent years. Another aspect that might be pointed out is that delays in gross motor skills, also using the TGMD-2 procedures and norms, have not been observed in other countries, such as in Hong Kong (Pang \& Fong, 2009). Such results clearly indicate that besides organism influences, such as maturation, other aspects definitely play an important role even in the development of gross motor skills.

Influence of multiple aspects in motor skill mastering, even of those named gross motor skills, may also be observed in our results. A few previous studies have already demonstrated the importance and the benefits of intervention programs in fundamental motor skills in children (Braga, Krebs, Valentini, \& Tkac, 2009; Brauner \& Valentini, 2009; Lopes, Lopes, \& Pereira, 2004). However, such studies showed improvement in motor skill performance due to specific intervention programs and our results show the effects due to physical education program in the regular school curriculum. Such results are important for several reasons. First, if opportunity of practice and appropriate instruction are provided at ages in which children are most responsive, considering the sensitive periods (Bornstein, 1989), mastering of gross motor skills should be achieved and with better developmental levels. In this case, it has been suggested that gross motor skills should be refined around the age of 7- and 8-year (Clark, 2007; Gallahue \& Donnelly, 2007) and regular physical education activities, according to our results, are crucial. Second, mastering of fundamental motor skills at proper age, due to regular physical education, children would not be delayed in their motor development and would not need to be enrolled in specific programs in order to promote fundamental motor skills, because regular physical activities at school would already have provided the proper stimulus and necessary practice to promote development of such skills to the desirable levels.

Difficulties in efficiently perform fundamental motor skills, usually observed in children, as showed in several studies (Bonifacci, 2004; Braga, Krebs, Valentini, \& Tkac, 2009; Brauner \& Valentini, 2009) might affect the desirable motor development improvement. When such effect occur, lack of skillfulness in performing fundamental motor skills constitute a proficiency barrier, as suggested (Clark, 2007; Gallahue \& Donnelly, 2007; Seefeldt \& Haubenstricker, 1982). Therefore, physical education activities in regular school and provided by a specialist teacher, even in kindergarten, might become decisive to promote gross motor development improvements and grant children possibilities to continue in their motor development course.

Finally, our results corroborate results of a previous study (Pang \& Fong, 2009) in which was observed that children from 
Hong Kong demonstrated better performance of gross motor skills compared to Brazilian and American children. Pang and Fang (2009) suggested that these differences might be due to the school system differences among the places, and children from Hong Kong would have showed a better gross motor development because of regular physical education. In the present study, which employed a controlled design, direct evidences of the effects of regular physical education on gross motor skill proficiency were obtained. Physical education, even in kindergarten, improved gross motor performance of children in performing both locomotor and object control skills.

\section{Conclusion}

Results from this study showed that gross motor development is influenced by regular physical education activities, ministered by a specialist, compared to recreational activities ministered by a regular classroom teacher in kindergarten. In this way, we suggested that structured practice and appropriate instruction provided by physical education teacher are crucial in promoting gross motor development even in young age such as in kindergarten.

\section{Acknowledgements}

We are grateful to the children and to the staff of School Crispiniano Soares, to FAPESP, grant \# 2010/00032-1, and to Secretaria Estadual de Educação do Estado de São Paulo.

\section{REFERENCES}

Bonifacci, P. (2004). Children with low motor ability have lower visualmotor integration ability but unaffected perceptual skills. Human Movement Science, 23, 157-168. doi:10.1016/j.humov.2004.08.002

Bornstein, M. H. (1989). Sensitive periods in development: Structural characteristics and causal interpretations. Psychological Review, 105, 179-197.

Braga, R. K., Krebs, R. J., Valentini, N. C., \& Tkac, C. M. (2009). A influência de um programa de intervenção motora no desempenho das habilidades locomotoras de crianças com idade entre 6 e 7 anos. Revista da Educação Física/UEM, 20, 171-181.

Brauner, L. M., \& Valentini, N. C. (2009). Análise do desempenho motor de crianças participantes de um programa de atividades físicas. Revista da Educação Física/UEM, 20, 205-216.

Clark, J. E. (1994). Motor development. Encyclopedia of Human Behavior, 3, 245-255.

Clark, J. E. (2007). On the problem of motor skill development. JOP$E R D, 78,39-45$.
Cools, W., Martelaer, K., Samaey, C., \& Andrias, C. (2008). Movement skill assessment of typically developing preschool children: A review of seven movement skill assessment tools. Journal of Sports Science and Medicine, 8, 154-168.

Gallahue, D. L. (1982). Understanding motor development in children. Boston, MA: John Wiley \& Sons, Inc.

Gallahue, D. L., \& Donnelly, F. C. (2007). Developmental physical education for all children (4th ed.). Urban-Champaign, IL: Human Kinetics.

Houwen, S., Hartman, E., Jonker, L., \& Visscher, C. (2010). Reliability and validity of the TGMD-2 in primary-school-age children with visual impairments. Adapted Physical Activity Quarterly, 27, 143159.

Lopes, L., Lopes, V. P., \& Pereira, B. (2004). Atividade física no recreio escolar: Estudo de intervenção em crianças dos seis aos 12 anos. Revista Brasileira de Educação Física e Esporte, 20, 271-280.

Niemeijer, A. S., Smits-Engelsman, B. C. M., \& Schoemaker, M. M. (2007). Neuromotor task training for children with developmental coordination disorder: A controlled trial. Developmental Medicine \& Child Neurology, 49, 406-411. doi:10.1111/j.1469-8749.2007.00406.X

Pang, A. W.-Y., \& Fong, D. T.-P. (2009). Fundamental motor skill proficiency of Hong Kong children aged 6 - 9 years. Research in Sports Medicine, 17, 125-144. doi:10.1080/15438620902897516

Seefeldt, V., \& Haubenstricker, J. (1982). Patterns, phase, or stages: An analytical model for the study of developmental movement. In J. A. S. Kelso, \& J. E. Clark (Eds.), The development of movement control and coordination (pp. 309-318). New York, NY: John Wiley \& Sons, Ltd.

Staples, K. L., \& Reid, G. (2010). Fundamental movement skills and autism spectrum disorders. Journal of Autism and Developmental Disorders, 40, 209-217. doi:10.1007/s10803-009-0854-9

Thelen, E. (1986). Development of coordinated movement: Implications for early human development. In M. G. Wade, \& H. T. A. Whiting (Eds.), Motor development in children: Aspects of coordination and control (pp. 106-119). Boston, MA: Martin Nijhoff.

Thelen, E. (1995). Motor development: A new synthesis. American Psychologist, 50, 79-95. doi:10.1037/0003-066X.50.2.79

Thelen, E. (2000). Grounded in the world: Developmental origins of the embodied mind. Infancy, 1, 3-28. doi:10.1207/S15327078IN0101 02

Ulrich, B. D. (1989). Development of stepping patterns in human infants: A dynamical systems perspective. Journal of Motor Behavior, 21, 392-408.

Ulrich, D. A. (2000). Test of gross motor development-2 (2nd ed.). Austin, TX: PRO-ED.

Valentini, N., \& Rudisill, M. (2004). Motivacional climate, motor-skill development, and perceived competence: Two studies of developmentally delayed kindergarten children. Journal of Teaching in Physical Education, 23, 216-234. 